\title{
Original article \\ Concordance between Stages of Behavior Change Questionnaire and IPAQ
}

\author{
Priscila Missaki Nakamura \\ Camila Bosquiero Papini \\ Inaian Pignatti Teixeira \\ São Paulo State University at Rio Claro, Brazil \\ Emerson Sebastião \\ University of Illinois at Urbana-Champaign, USA \\ Sebastião Gobbi \\ São Paulo State University at Rio Claro, Brazil \\ Kelly Lynn Cordeira \\ Federal University of Pelotas, Brazil \\ Eduardo Kokubun \\ São Paulo State University at Rio Claro, Brazil
}

\begin{abstract}
A low rate of physical activity (PA) participation is observed worldwide. The identification of feasible and reliable instruments able to accurately measuring PA and help in the development of interventions to promote PA are necessary. This study aimed to analyze the concordance between the Stages of Behavior Change Questionnaire (SBCQ) and the International Physical Activity Questionnaire (IPAQ long-version) in assessing adult leisure-time physical activity (LTPA). A total of 1.588 adults completed the IPAQ to assess LTPA and the participants who performed more than $10 \mathrm{~min} /$ week were classified in active individuals. Using the SBCQ, active individuals were those classified in the action or maintenance stage and inactive individuals were those classified in the precontemplation, contemplation or preparation stage. The concordance between SBCQ and IPAQ was found to be 0.80 . Separated by gender, it was observed a concordance between the two instruments of 0.82 for women, and 0.77 for men. Regarding age group, it was found to be 0.81 for young and middle-aged adults, and 0.77 for older people. The SBCQ presented a very good concordance with IPAQ to assess LTPA.
\end{abstract}

Keywords: assessment of physical activity, elderly, adults, behavior toward physical activity

Resumo- “Concordância entre o Questionário de Estágio de Mudança de Comportamento e IPAQ." Devido à baixa prática de atividade física no mundo, identificar instrumentos que possam avaliar o nível de (AF), além de necessário, podem ajudar no desenvolvimento de intervenções para promoção da AF. Objetivo deste estudo foi analisar a concordância entre o Questionário de Estágio de Mudança de Comportamento (QEMC) e o Questionário Internacional de Atividade Física (IPAQ- versão longa) em avaliar o tempo de atividade física no lazer (AFL). Para avaliar o nível de AFL, 1.588 adultos responderam IPAQ e participantes que realizaram mais de 10 min/ sem foram classificados como ativos. Através do QEM os indivíduos foram classificados no estágio de ação ou manutenção e os inativos classificados no precontemplação, contemplação ou preparação. Concordância entre QEMC e o IPAQ foi 0,80, para as mulheres de 0,82, homens 0,77, adultos e adultos meia idade 0,81 e idosos 0,77. QEMC apresentou boa concordância com IPAQ para avaliar a AFL.

Palavras-chaves: avaliação da atividade física, idosos, adultos, comportamento para atividade física

Resumen-“Concordancia entre el Internado Cuestionario cambio de comportamiento y IPAQ." Existe la necesidad de identificar los instrumentos que permitan evaluar el nivel de actividad física (AF) y ayudar a desarrollar intervenciones para promover la AF, debido a la práctica bajo PA en el mundo. Objetivo fue analizar la correlación entre el cuestionario Stage Cambio de Comportamiento (CSCC) y el Cuestionario Internacional de Actividad Física (IPAQ versión larga) para evaluar el tiempo de actividad física de ocio (AFO). 1588 adultos respondieron IPAQ para evaluar el nivel de AFO y los participantes que realicen más de 10 min / semana fueron clasificados como activos. A través de los temas CSCC se clasificaron en la etapa de acción y mantenimiento 
inactivo o clasificado en precontemplación, contemplación o preparación. Acuerdo entre el IPAQ y CSCC fue de 0,80. Para las mujeres 0,82, 0,77 los hombres, adultos y adultos de mediana edad y adultos mayores 0,81 0,77. CSCC mostró buen acuerdo con IPAQ para evaluar la AFO.

Palabras claves: evaluación de la actividad física, los adultos mayores, el comportamiento de la actividad física

\section{Introduction}

The benefits of physical activity (PA) health are well understood (Garber et al., 2011; Wen et al., 2011). However, the global prevalence of PA ranges from $17 \%$ in Southeast Asia to $43 \%$ in the Americas and in Eastern Mediterranean countries.

A major challenge of the 21 st century concerning health is related to changes in PA level due to societal trends that are leading to less activity than before (Hallal et al., 2012). Thus, there is an international interest in developing interventions to increase PA at the population level (Kohl et al., 2012).

To develop interventions to promote PA, several studies have used the Transtheoretical Stages of Behavioral Change (SBC) Model (Gorczynski, Faulkner, \& Cohn, 2010; Si et al., 2011; Tuah, Amiel, Qureshi, Car, Kaur, \& Majeed, 2011). This model describes how people move dynamically through five different stages of behavioral change. Through identifying the relevance of a specific health behavior in a person's life using an assessment algorithm, people can be classified into a stage of change: precontemplation, contemplation, preparation, action, or maintenance (Dishman 1994). The Stages of Behavioral Change Questionnaire (SBCQ) was developed to properly classify individuals into a stage of change to fit into the SBC model. One of the great advantages of classifying individuals into these stages is the possibility of developing tailored interventions to promote PA that are may be more effective.

The SBCQ may also be useful in identifying important information on PA levels. In the SBC model, three stages may be associated with being inactivity (precontemplation, contemplation, and preparation) and two stages are associated with being activity (action and maintenance). Therefore, it has been suggested in the literature that the SBCQ can be used in surveillance evaluation studies (Booth, Macaskill, Owen, Oldenburg, Marcus, \& Baumanm, 1993; Dumith, Gigante, \& Domingues, 2007; Garber, Allsworth, Marcus, Hesser, \& Lapane, 2008; Laforge, Velicer, Richmond, \& Owen, 1999). Since the SBCQ was not developed for such purpose, studies are needed to examine whether the SBC is able to accurately predict PA level.

The International Physical Activity Questionnaire (IPAQ) has been used in several Brazilian evaluation studies (Hallal, Dumith, Bastos, Reichert, Siqueira, \& Azevedo, 2007) and worldwide (Hallal et al, 2012). This questionnaire has a short version (seven questions) and long version (27 questions) that evaluate the frequency and duration of activities performed in the last seven days within four different domains of PA (leisure-time, transportation, household activities, and occupational) (Craig et al., 2003). Although the IPAQ can reasonably estimate leisure-time physical activity (LTPA) and the time spent in community activities, studies have shown that the IPAQ overestimates PA in the other two PA domains including, household activities and physical labor (Ekelund, Neovius, Linne, \& Rossner, 2006; Hallal et al., 2010; Johnson-Kozlow, Sallis, Gilpin, Rock, \& Pierce, 2006; Ramírez-Marrero, Rivera-Brown, Nazario, RodríguezOrengo, Smit, \& Smith, 2008; Sebastião et al., 2012). Further, the IPAQ is unable to identify factors that enable people to change their behavior. This lack of information jeopardize the development of effective activities and interventions tha can be offered to the population.

In the literature, there are studies that have used either the IPAQ or the SBCQ to evaluate PA at the population level. Additionally, it has been observed that the SBCQ presents some advantages over the IPAQ (e.g. the SBCQ has only one question, it is faster to be applied and it can orientate PA interventions). However, it is important to examine whether the SBCQ is able to classify people as active and/ or inactive. Thereby, this study aimed to analyze the concordance between the SBCQ and the IPAQ-long version to assess LTPA in adults.

\section{Methods}

A cross-sectional, population-based study was conducted in Rio Claro, Brazil. Rio Claro has nearly 190,000 inhabitants and the focus of this study was adults aged 20 years and over. Data were collected from 20072008. The sampling process was conducted in several stages. First, from the 200 census tracts, all odd census tracts $(n=97)$ were selected. To at least half of the possible census tracts $(n=100)$ the 50,100 , and 150 census tracts were added to the sample. Following, all the households of each sampled tract were listed and seven households were systematically selected. This yielded a total of 700 households. All residents of the sampled households aged 20 or over were eligible for the study. Those who refused to answer the door or were not found at home at the time were visited at least in two other occasions. The São Paulo State University Ethical Committee approved the research protocol number (3151), and informed consent was obtained from each subject before data collection.

A total of 1,588 individuals were interviewed. Section four of the long version of the IPAQ in Portuguese was employed to assess LTPA levels related to recreation, sports, and other LTPA using seven-day recall period. The LTPA 
score was calculated as the weekly time (in minutes) spent in moderate-intensity activities (including walking) plus twice the weekly time spent in vigorous-intensity activities, as proposed by Hallal et al. (2003). Individuals with a score of 0 to $9 \mathrm{~min} /$ week were considered inactive; those with scores of $10 \mathrm{~min} /$ week or more were considered active enough to improve health conditions.

The SBC was assessed using the questionnaire developed by Prochaska and Marcus (1992). The following question was asked: "Do you perform PA regularly during your leisure time (excluding household activities, occupational, and transportation) for at least 10 continuous minutes a week?" Individuals were then categorized into a SBC model stage of change accordingly: precontemplation, individuals do not change their high risk behavior in the foreseeable future (six months); contemplation, people seriously intended to change their behavior in the next six months; preparation, individuals intend to take action in the near future, usually in less than six months; action, individuals have made overt behavior changes within the past six months; and maintenance, individuals have changed their behavior for more than six months (Dishman, 1994).

Interviews were conducted by five men and 12 women. Those were selected to conduct the interviews after attending a 24-hour training on the correct application and coding of the questionnaire. Fieldwork supervisors applied a shortened version of the questionnaire to $10 \%$ of the randomly selected interviewees to test the reliability of some questions and to control the quality of the interviewers' results. Data were entered twice into Epi Info version 6.04 and were transferred to SPSS version 13, with which all analyses were conducted. Descriptive and analytics analyses were conducted.

\section{Statistical analysis}

Kappa was performed to verify the concordance between IPAQ and the SBCQ through Medical version 12.3.0.0.

\section{Results}

The final sample consisted of 1,581 adults $(46 \pm 16$ years; $n=914$ women aged $47 \pm 17.2$ years; $n=667$ men aged $45 \pm 16.7$ years). On average, both women and men were overweight (body mass index of $26 \pm 5.1$ and $26 \pm 4.5 \mathrm{~kg}$ / $\mathrm{m}^{2}$, respectively). Of the 1,581 individuals assessed by the IPAQ, 599 (38\%) were classified as active ( $\geq 10 \mathrm{~min} /$ week); and by means of the SBCQ, 545 (34.5\%) were classified in the active stages of SBC: the action and maintenance stage.

Of the 1,036 individuals who were classified as in precontemplation, contemplation, or preparation by the SBCQ, $936(90.3 \%)$ were classified as inactive by the IPAQ. Of the 545 individuals who were classified as in action and maintenance by SBCQ, 499 (91.5) were classified as active by IPAQ. Kappa analysis revealed that the concordance between SBCQ and IPAQ in evaluating LTPA was very good $(k=0.80 ; 95 \% \mathrm{CI}=0.77-0.83)$ (Table 1).

The concordance between SBCQ and IPAQ was similar for women $(k=0.82 ; 95 \% \mathrm{CI}$ : 0.78-0.86) and for men ( $k=0.77$; 95\% CI: 0.72-0.82) (Table 2).

Related to years, the concordance between SBCQ and IPAQ was similar for adults $(k=0.81 ; 95 \% \mathrm{CI}$ : $0.77-0.84)$ and for the elderly ( $k=0.77$; 95\% CI: $0.69-0.84)$ (Table 3$)$.

The distribution of the SBCQ according to the recommendations of PA (150 min/week) measured by IPAQ showed that $67.1 \%(n=365)$ of the participants who were classified in the action and maintenance stages were classified as active ( $\geq 150 \mathrm{~min} /$ week). Furthermore, $90.6 \%$ $(n=938)$ of participants who were classified as in precontemplation, contemplation, or preparation were classified as insufficiently active $(<150 \mathrm{~min} /$ week $)$.

\section{Discussion}

This study analyzed the concordance between the SBCQ and IPAQ-long version in assessing LTPA in adults. The findings suggest that the concordance is very good between the SBCQ and the IPAQ in assessing LTPA for all subgroups assessed.

In the present study, the concordance between the SBCQ and the IPAQ-long version in assessing LTPA, according to Kappa coefficient was 0.80 (table 1 ). This finding suggests that measuring PA using the SBCQ may be more accurate than using a logbook. Hasgstromer et al. (2006) explored the validity characteristics of the long-version IPAQ compared to a logbook in measuring LTPA (Mets.h/week ${ }^{-1}$ ) in 46 adults. The logbook consisted of one page for each day of the seven-day period in which the participant filled out the type of and time spent in PA (occupational, transportation, household activities, and leisure-time activities). The authors observed a correlation of $r h o=0.58$ between the IPAQ and the logbook. Although the logbook is a more comprehensive instrument than the SBCQ, it suggests that the concordance between the SBCQ and the IPAQ is better than the logbook and the IPAQ. It suggests that the SBCQ may be more useful in evaluation studies compared to logbook when it comes to the development of interventions to promote PA than a logbook.

The length of the SBCQ may improve accuracy in measuring PA levels in males and females. Regarding

Table 1. Concordance between Stages of Behavior Change Questionnaire (SBCQ) and International Physical Activity Questionnaire (IPAQ). Overall data.

\begin{tabular}{lccc}
\hline \multicolumn{4}{c}{ Leisure-time physical activity level } \\
\hline Stages of behavioral change & Inactive & Active & Total \\
& $\mathrm{n}(\%)$ & $\mathrm{n}(\%)$ & $\mathrm{N}$ \\
$\begin{array}{l}\text { Precontemplation, contemplation and } \\
\text { preparation }\end{array}$ & $938(90.5)$ & $98(9.5)$ & 1036 \\
$\begin{array}{l}\text { Action and maintenance } \\
\text { Kappa }\end{array}$ & $44(8.1)$ & $501(91.9)$ & 545 \\
\hline
\end{tabular}


Table 2. Concordance between Stages of Behavior Change Questionnaire (SBCQ) and International Physical Activity Questionnaire (IPAQ). Data representative of women and men. .

\begin{tabular}{lcccccc}
\hline \multicolumn{7}{c}{ Leisure-time physical activity level } \\
\hline Stages of behavioral change & $\begin{array}{c}\text { Women* } \\
\text { Inactive } \\
\mathrm{n}(\%)\end{array}$ & $\begin{array}{c}\text { Active } \\
\mathrm{n}(\%)\end{array}$ & Total n & $\begin{array}{c}\text { Inactive } \\
\mathrm{n}(\%)\end{array}$ & $\begin{array}{c}\text { Men* } \\
\text { Active } \\
\mathrm{n}(\%)\end{array}$ & Total n \\
$\begin{array}{l}\text { Precontemplation, } \\
\text { contemplation and } \\
\text { preparation }\end{array}$ & $587(92.7)$ & 46 & 633 & 349 & $54(13.4)$ & 403 \\
$\begin{array}{l}\text { Action and maintenance } \\
\text { Kappa }\end{array}$ & $(7.3)$ & & $(96.6)$ & & \\
*Three women and four men were excluded from the analysis. & 256 & 281 & 21 & 243 & 264 \\
\end{tabular}

Table 3. Concordance between Stages of Behavior Change Questionnaire (SBCQ) and International Physical Activity Questionnaire (IPAQ). Data presented separated by adults and elderly.

\begin{tabular}{|c|c|c|c|c|c|c|}
\hline \multirow[b]{3}{*}{$\begin{array}{l}\text { Stages of behavioral } \\
\text { change }\end{array}$} & \multicolumn{3}{|c|}{ Leisure-time physical activity level } & \multirow{2}{*}{\multicolumn{3}{|c|}{ Elderly* }} \\
\hline & & ult* & & & & \\
\hline & $\begin{array}{c}\text { Inactive } \\
\mathrm{n}(\%)\end{array}$ & $\begin{array}{c}\text { Active } \\
\mathrm{n}(\%)\end{array}$ & Total $n$ & $\begin{array}{c}\text { Inactive } \\
\mathrm{n}(\%)\end{array}$ & $\begin{array}{c}\text { Active } \\
\mathrm{n}(\%)\end{array}$ & Total $n$ \\
\hline Precontempation, & 716 & 77 & 793 & 219 & 23 & 242 \\
\hline $\begin{array}{l}\text { Contemplation and } \\
\text { Preparation }\end{array}$ & $(90.3)$ & $(9.7)$ & & $(90.5)$ & $(9.5)$ & \\
\hline $\begin{array}{l}\text { Preparation } \\
\text { Action and Maintenance }\end{array}$ & $\begin{array}{c}34 \\
(7.8)\end{array}$ & $\begin{array}{c}400 \\
(92.2)\end{array}$ & 434 & $\begin{array}{c}13 \\
(11.7)\end{array}$ & $98(88.3)$ & 111 \\
\hline Kappa & & & 0.81 & & & 0.77 \\
\hline
\end{tabular}

*Six adults and two elderly were excluded from the analysis.

Table 4. Distribution (n - \%) of all participants in levels of LTPA according to the Stages of Behavior Change Questionnaire (SBCQ) and the International Physical Activity Questionnaire (IPAQ).

\begin{tabular}{lcccc}
\hline \multicolumn{4}{c}{ Leisure-time physical activity level } & \\
\hline Stages of behavior change & Active & Insufficiently active & Sedentary & Total \\
& $(\geq 150 \mathrm{~min} /$ week $)$ & $(<150 \mathrm{~min} /$ week $) \mathrm{n}$ & $(0$ min/week $)$ & $\mathrm{n}(\%)$ \\
$\begin{array}{l}\text { Precontemplation, } \\
\begin{array}{l}\text { Contemplation and } \\
\text { Preparation }\end{array}\end{array}$ & $49(4.7)$ & $938(90.6)$ & $49(4.7)$ & 1036 \\
Action and Maintenance & $365(67.1)$ & & & \\
*One participant was excluded from the analysis. & $43(7.9)$ & $136(25.0)$ & 544 \\
\hline
\end{tabular}

gender, the concordance was found to be very good for both women $(k=0.82)$ and men $(k=0.77)$ in this study. However, other studies that evaluated the concordance between the IPAQ and other indirect instruments have shown differences in the concordance between genders. Benedetti et al showed that the concordance between the IPAQ and the Bouchard's Physical Activity Diary to assess PA was better for older women $(k=0.37)$ than older men $(k=0.04)$ (Benedetti, Antunes, Rodriguez-Añez, Mazo, \& Petroski; 2007; Benedetti, Mazo, \& Barros, 2004). Similar findings were observed by Guedes, Lopes and Guedes, (2005) in a study on teenagers. Teenager girls (younger than 14 years old) had a better kappa index when evaluated by the IPAQ and the Bouchard Diary $24 \mathrm{~h}$ than boys during sitting $(\mathrm{k}=0.06$ girls; 0.01 boys), walking ( $k=0.13$ girls, 0.07 boys), and moderate-intensity exercise ( $k=0.09$ girls; $k=0.07$ boys). Compared to the above instruments, the SBCQ has only one question, which may decrease the risk of people answering the question in the wrong way. Thus, the similarity of concordance between genders that was showed in the present study may be related to the number of questions of The SBCQ. However, more studies are needed to verify whether men and women have difficulties in completing the PA questionnaires.

The SBCQ may be appropriate for the older population. Regarding age, the results of this study showed similar concordance for the SBCQ and the IPAQ between adults $(k=0.81 ; 95 \% \mathrm{CI}: 0.77-0.84)$ and the older participants $(k=0.77 ; 95 \%$ CI: $0.69-0.84)$. These results suggest that the SBCQ may be able to decrease some difficulties that older people may have in answering questionnaires. Heesch, Uffelen, Hill, and Brown (2010) verified that older adults have difficulties in understanding and recalling information when employing the IPAQ. Specifically, errors included recalling PA in an "average" week, not in the previous sevendays; recalling PA lasting < 10 minutes/session; reporting the same PA twice or three times; including the total time of activity for which only part of that time was at the 
intensity specified in the question. Participants struggled mostly on questions related to moderate-intensity PA and walking than those related to vigorous-intensity PA. According to Stewart, Mills, King, Haskell, Gillis, and Ritter (2001) memory and cognitive issues influence older people's ability to evaluate their PA level; thus, questions that require memory recall may be answered inaccurately. Furthermore, Yusuf, Croft, Giles, Anda, Carpersen, and Jones (1996) found that older people are most likely to engage in daily activities such as walking, gardening, and golf, which are not included in the IPAQ. Thus, for this population, the SBCQ may be a better option of instrument to measure PA levels than the IPAQ or other long questionnaires requiring memory recall.

The SBCQ may be better at classifying inactivity than activity. At this study, the participants who were classified in the inactive stages (precontemplation, contemplation, or preparation) by the SBCQ, 91\% were classified as insufficiently active ( $<150 \mathrm{~min} /$ week) by the IPAQ (Refer to Table 4). This suggests that these participants may have done some exercise in the previous six months (precontemplation, contemplation, or preparation) but not enough to reach the recommended $150 \mathrm{~min} / \mathrm{week}$. Moreover, the high agreement in classification, suggests that the SBCQ may be used to assess inactivity levels.

However, in this study, $25 \%$ of the people who were classified in the active stages (action or maintenance) by the SBCQ were classified as sedentary (0 min/week) by the IPAQ. To possible explanations for this results are: First, the IPAQ questionnaire has one specific question about moderate-intensity exercise and another about vigorous-intensity exercise, whereas the SBCQ does not separate PA by intensity level. Thus, people who engage in light-intensity exercise are not able to report it on the IPAQ, but can report it on SBCQ resulting in a discrepancy in activity level classifications. Second, the IPAQ questions are related to exercise that people engaged in seven days prior to the interview and the SBCQ questions are related to six months before the interview. PA levels can change based on the time frame considered and may have also contributed to the differences in classification.

This study presents some strength. This study was developed with 1,588 participants who were selected through a complex survey design that guaranteed a representativeness of the city. All interviewers attended a 24-hour training course on the correct application and coding of the questionnaires. Moreover, the present study used the IPAQ to verify a concurrent validity of the SBCQ to evaluate the physical activity level. Previously, the IPAQ has shown a moderate correlation between accelerometry, pedometer, doubly labeled water, physical activity log, and maximum oxygen consumption methods Poppel, Chinapaw, Mokkink, Mechelen, and Terwee (2010). Craig et al (2003) examined the international reliability and validity of the IPAQ questionnaire to determine PA levels using accelerometry. To determine the criterion validation, the authors used the accelerometer (CSA model 7164) against the IPAQ. The 744 participants from 12 countries wore the monitors for seven days and completed the IPAQ longversion questionnaire. The agreement was fair-to-moderate between the two measures ( $r h o=0.33,95 \% \mathrm{CI}=0.26-0.39$ ). Cocker, Bourdeaudhuij, and Cardon (2009) found strong correlations $(r h o=0.37)$ between step counts through pedometer and total PA reported by the long-form IPAQ for 310 healthy adults with a mean age 38.7 (standard deviation=11.9) years. Furthermore, the IPAQ questionnaire has been used worldwide to verify the PA prevalence (Abu-Omar, \& Rütten, 2008; Center for Disease Control and Prevention, 2008; Craig et al., 2003; Hallal et al., 2012; Peclova, Vašícková, Frömelm, \& Djordjeviæm, 2009). Therefore, choosing the IPAQ questionnaire to examine the accuracy of the SBCQ to classify a representative, large sample of people as active or inactive could be considered the strength of this study.

Additional studies are needed to confirm whether the SBCQ can evaluate the PA level during leisure-time using direct instruments to evaluate PA level (eg. accelerometer, pedometer). This study showed that the SBCQ may have better concordance with the IPAQ than Bouchard's Physical Activity Diary, Behavioral Risk Factor Evaluation System, and PA diaries; however these instruments are subjective and may be biased by over- or under-reporting. Furthermore, additional studies in different population and settings need to be conducted to confirm the validity of the SBCQ to evaluate LTPA level.

\section{Conclusion}

The SBCQ showed a high concordance with the IPAQ in assessing LTPA in the studied sample. The SBCQ also show high concordance among age and gender. This study provides evidence that the SBCQ instrument can reasonable assess LTPA, which may provide clues for the development of tailored strategies and interventions based on the SBC health promotion model.

\section{References}

Abu-Omar, K. \& Rütten, A. (2008). Relation of leisure time, occupational, domestic, and commuting physical activity to health indicators in Europe. Preventive Medicine, 47 (3), 319-323. PubMed doi: 10.1016/j.ypmed.2008.03.012

Benedetti, T.R.B., Mazo, G.Z., \& Barros, M.V.G.(2004). Application of the International Physical Activity Questionnaire (IPAQ) for evaluation of elderly women: concurrent validity and test-retest reproducibility. Revista Brasileira Ciência e Movimento, 12(1), 25-34.

Benedetti, T.R.B., Antunes, P.C., Rodriguez-Añez, C.R., Mazo, G.Z., \& Petroski, E.L. (2007). Reproducibility and validity of the International Physical Activity Questionnaire (IPAQ) in elderly men. Revista Brasileira de Medicina do Esporte, 13 (1), 9e13e. PubMed doi: 10.1590/S1517-86922007000100004

Booth, M., Macaskill, P., Owen, N., Oldenburg, B., Marcus, B., \& Baumanm, A. (1993). Population prevalence and correlates of 
stages of change in physical activity. Health Education and Behavior, 20(3), 431-440. PubMed doi: 10.1177/10901981930 2000312

Center for Disease Control and Prevention (2008). Behavioral Risk Factors Surveillance System Survey Data. Atlanta, Georgia: US Department of Health and Human Services, Center for Disease Control and Prevention.

Cocker, K.A.D., Bourdeaudhuij, I.M.D., \& Cardon, G.M. (2009). What do pedometer counts represent? A comparison between pedometer data and data from four different questionnaires. Public Health Nutrition, 12 (1), 74-81. PubMed doi: 10.1017/ S1368980008001973

Craig, C.L., Marshall, A.L., Sjostrom, B.A.E., Booth, M.L., Ainsworth, B.E., Pratt, M., . . \& \& Oja, P. (2003). International Physical Activity Questionnaire: 12-Country reliability and validity. Medicine \& Science in Sports \& Exercise, 35(8), 13811395. PubMed doi: 10.1249/01.MSS.0000078924.61453.FB

Dishman, R.K. (1994). Advances in exercise adherence. Champaign, IL: Human Kinetics.

Dumith, S.C., Gigante, D.P., \& Domingues, M.R. (2007). Stages of change for physical activity in adults from Southern Brazil: a population-based survey. International Journal of Behavioral Nutrition and Physical Activity, 4 (25), 1-10. PubMed doi: 10.1186/1479-5868-4-25

Ekelund, U., Neovius, M., Linne, Y., \& Rossner, S. (2006). The criterion validity of a last 7-day physical activity questionnaire (SAPAQ) for use in adolescents with a wide variation in body fat: the Stockholm Weight Development Study. International Journal Obesity, 30(6),1019-1021.

Garber, C.E., Allsworth, E., Marcus, B.H., Hesser, J., \& Lapane, K.L. (2008). Correlates of the Stages of Change for Physical Activity in a Population Survey. American Journal of Public Health, 98 (5), 897-904. PubMed doi: 10.2105/ AJPH.2007.123075

Garber C.E., Blissmer, B., Deschenes, M.R., Franklin, B., Lamonte, M.J., Lee, I.M., . . \& Swain, D.P. (2011). Quantity and quality of exercise for developing and maintaining cardiorespiratory, musculoskeletal, and neuromotor fitness in apparently healthy adults: guidance for prescribing exercise. Medicine \& Science in Sports \& Exercise, 43 (7), 1334-1359. PubMed doi: 10.1249/ MSS.0b013e318213fefb

Gorczynski, P., Faulkner, G., \& Cohn, T. (2010). Exploring the construct validity of the transtheoretical model to structure physical activity interventions for individuals with serious mental illness. Psychiatric Rehabilitations Journal, 34(1), 61-64. PubMed doi: 10.2975/34.1.2010.61.64

Guedes, D.P., Lopes, C.C., \& Guedes, J.E.R.P. (2005). Reprodutibilidade e validade do Questionário Internacional de Atividade Física em adolescentes. Revista Brasileira de Medicina do Esporte, 11(2),151-58. PubMed doi: 10.1590/S151786922005000200011

Hagstromer, M., Oja, P., \& Sjostrom, M. (2006). The International Physical Activity Questionnaire (IPAQ): a study of concurrent and construct validity. Public Health Nutrition, 9(6), 755-762. PubMed doi: 10.1079/PHN2005898

Hallal, P.C., Victoria, C.G., Wells, J.C.K., \& Lima, R.C. (2003). Physical inactivity: prevalence and associated variables in Brazilian adults. Medicine \& Science in Sports \& Exercise, 35(11), 1894-1900. PubMed doi: 10.1590/S0102-311X2005000 200024

Hallal, P.C., Dumith, S.C., Bastos, J.P., Reichert, F.F., Siqueira, F.V., \& Azevedo M.R. (2007). Evolution of the epidemiological research on physical activity in Brazil: a systematic review.
Revista de Saúde Pública 41(3), 453-60. PubMed doi: 10.1590/ S0034-89102007000300018

Hallal, P.C., Gomez, L.F., Parra, D.C., Lobelo, F., Mosquera, J., Florindo, A.A., . . \& \& Sarmiento, O.L. (2010). Lessons Learned After 10 Years of IPAQ Use in Brazil and Colombia. Journal of Physical Activity and Health, 7(2), 259-64.

Hallal, P.C., Andersen, L.B., Bull, F.C., Guthold, R., Haskell, W., \& Ekelund, U. (2012). Global physical activity levels: surveillance progress, pitfalls, and prospects. Lancet, 380(9838), 247-57. PubMed doi: 10.1016/S0140-6736(12)60646-1

Heesch, K.C., Uffelen, J.G.Z.V., Hill, R.L., \& Brown, W.J. (2010). What do IPAQ questions mean to older adults? Lesson from cognitive interviews. International Journal of Behavioral Nutrition and Physical Activity, 7, 35. PubMed doi:10.1186/ 1479-5868-7-35

Johnson-Kozlow, M., Sallis, J.F., Gilpin, E.A., Rock, C.L., \& Pierce, J.P. (2006). Comparative validation of the IPAQ and the 7-Day PAR among women diagnosed with breast cancer. International Journal of Behavioral Nutrition and Physical Activity, 3(7), 259-S264. PubMed doi: 10.1186/1479-5868-3-7

Kohl, H.W., Craig, C.L., Lambert, E.V., Inove, S., Alkandari, J.R., Leetongin, G., \& Kahlmeier, S. (2012). The pandemic of physical inactivity: global for public health. Lancet, 380(9838), 294-305. PubMed doi: 10.1016/S0140-6736(12)60898-8

Laforge, R.G., Velicer, W.F., Richmond, R.L., \& Owen, N. (1999). Stage distributions for five health behaviors in the United States and Australia. Preventive Medicine, 28(1), 61-74. PubMed doi:10.1006/pmed.198.0384

Peclova, J., Vašícková, J., Frömelm, K., \& Djordjevicm, I. (2009). Leisure time, occupational, domestic and commuting physical activity of inhabitants of the Czech Republic aged 55-69: influence of socio-demographic and environmental factors. Acta Uniersitatis Palackanae Olomucensis Gymnica, 39(3), 1320.

Poppel, M.N.M.V., Chinapaw, M.J.M., Mokkink, L.B., Mechelen, W.V., \& Terwee, C.B. (2010). Physical activity questionnaires for adults: a systematic review of measurement properties. Sports Medicine, 40(7), 565-600. PubMed doi: 10.2165/ 11531930-000000000-00000

Prochaska, J.O., DiClemente, C.C., \& Noscross, J.C. (1992). In search of how people change: applications to addictive behaviors. American Psychologist, 47( 9), 1102-1114. PubMed doi: 10.1037/0003-066X.47.9.1102

Ramírez-Marrero, F.A., Rivera-Brown, A.M., Nazario, C.M., Rodríguez-Orengo, J.F., Smit, E., \& Smith, B.A. (2008). Selfreported physical activity in Hispanic adults living with HIV: comparison with accelerometer and pedometer. Journal of Association of Nurses in AIDS Care, 19(4), 283-294. PubMed doi: 10.1016/j.jana.2008.04.003

Si, Q., Yu, K., Cardinal, B.J., Lee, H., Yan, Z., Loprinzi, P.D.,. . . \& Liu, H. (2011). Promoting exercise behavior among Chinese youth with hearing loss: a randomized controlled trial based on the transtheoretical model. Psychological Reports, 109(3), 896906.

Stewart, A.L., Mills, K.M., King, A.C., Haskell, W.L., Gillis, D., \& Ritter, P.L. (2001). CHAMPS physical activity questionnaire for older adults: outcomes for interventions. Medicine \& Science in Sports \& Exercise, 33(7), 1126-1141. PubMed doi: 10.1097/ 00005768-200107000-00010

Tuah, N.A., Amiel, C., Qureshi, S., Car, J., Kaur, B., \& Majeed, A. (2011). Transtheoretical model for dietary and physical exercise modification in weight loss management for overweight and obese adults. Cochrane Database of Systematic Reviews, 10, 
Art.No.: CD008066. PubMed doi: 10.1002/14651858.CD008066

Wen, C.P., Wai, J.P.M., Tsai, M.K., Yang, Y.C., Cheng, T.Y.D.C., Lee, M., . . \& \& Wu, X. (2011). Minimum amount of physical activity for reduced mortality and extended life expectancy: a prospective cohort study. Lancet, 378(9798), 1244-53. PubMed doi:10.1016/S0140-6736(11)60749-6

Yusuf, H.R., Croft, J.B., Giles, W.H., Anda, R.F., Carpersen, C.J., \& Jones, D.A. (1996).Leisure-time physical activity among older adults-United States, 1990. Archives of International Medicine, 156(12), 1321-1326. PubMed doi: 10.1001/archinte.1996. 00440110093012.

\section{Authors' note}

Priscila Missaki Nakamura is postdoctoral fellow at the Federal University of Pelotas (2013).

Camila Bosquiero Papini and Inaian Pignatti Teixeira are PhD students in biodynamics of human movement at São Paulo State University.

Emerson Sebastião is a PhD student in kinesiology with Prof. Dr. Wojtek Chodzko Sajko and Dra. Andiara Schwingel at University of Illinois at Urbana Champaign, College of Applied Health Sciences

Sebastião Gobbi is an associate professor at São Paulo State University (UNESP) in Rio Claro and is research coordinator of the Laboratory of physical Activity and Aging (LAFE)

Kelly Lynn Cordeira currently works in the Center for Disease Control and Prevention at Atlanta.

Eduardo Kokubun is full professor at São Paulo State University where holds the position of Dean of Graduate Studies.

\section{Acknowledgments:}

The authors thank the Fundação Municipal de Saúde de Rio Claro, São Paulo, Brazil; the Conselho Regional de Educação Física do Estado de São Paulo (CREF4/SP), Fundação de Amparo à Pesquisa do Estado de São Paulo, and CAPES.

\section{Correspondence to:}

Priscila M Nakamura Av. 24-A, 1515, Bela Vista, 13506-900, Rio Claro, SP, Brazil

Phone: 55 11-99232-4088

e-mail:pri_nakamura@yahoo.com.br

Manuscript received on December 6, 2012

Manuscript accepted on June 22, 2013

Motriz. Journal of Physical Education. UNESP, Rio Claro, SP, Brazil, eISSN: 1980-6574, is licenced under a Creative Commons License, Version 3.0. 